\title{
MODELLING OF A LESSON IN THE CONTEXT OF COMPETENCE APPROACH
}

\author{
Olexandra Savchenko \\ Doctor of Sciences in Pedagogy, Professor \\ Full Member (Academician) of the National Academy of Educational Sciences of Ukraine \\ Chief Researcher at the Primary Education Department of the Institute of Pedagogics \\ National Academy of Educational Sciences of Ukraine, Ukraine \\ info@apsu.org.ua \\ $+380444843774$ \\ ORCID ID 0000-0001-5040-0860
}

\begin{abstract}
The types of educational results of primary school pupils have been determined: personal, subject-related, intersubject, metasubject, which are formed on intersubject basis, on the grounds of the systematic, competence-based and technological approaches. Didactic conditions of their implementation are the organization of pupils' subject to subject interaction, favorable psycho-didactic lesson environment, a variety of organizational forms of learning, and the choice of educational technology that meets the objectives and expected results of the lesson.
\end{abstract}

Keywords: educational results; lesson structure; systematic; competence-based and technological approaches; types of educational technologies.

\section{INTRODUCTION}

The boost of the efficiency of a lesson has become especially topical recently. It is caused by several circumstances: the importance of this form of learning, which remains a major one in the elementary school; the necessity of achieving obligatory educational results by pupils provided the variability of textbooks usage, availability of a wide choice of educational kits; new understanding of the essence of educational results and the necessity to measure them in the context of the competence approach.

Theoretical studies of the essence of the competence-based approach and experience of its use in the methods of individual subjects in the primary education have reached a considerable extent. Together with this, in our view, remain insufficiently elaborated didactic and methodological aspects of a lesson, where systematic and purposeful formation of each pupil's subject-related and key competencies should take place.

\section{THE OBJECTIVE OF THE ARTICLE}

In this regard, the problem of complying with the requirements to pupils' educational achievements determined by the program, is becoming especially topical. This makes the need for systematic studies dealing with understanding the new results of primary education and management the process of their achievement. The new situation in primary education development requires a teacher's focus on effective component of the lesson. 


\section{PRESENTATION OF THE BASIC MATERIAL}

1. The results of primary education are not confined only to educational achievements, they should be much broader. The expansion and specification of educational result must be borne in mind. As we understand, it should reflect the following types of achievements of a younger schoolchild:

- personal - revealing the influence of learning, environment, life experiences on the development of the sensual sphere, pupil's personal qualities, his socialization; characterizing the system of values, attitudes;

- subject-related - revealing a pupil's educational achievements in relation to mastering the components of the subject competence defined by the program, among which personal experience of the application of knowledge and skills gains a special importance;

- intersubject - may have a different range: be based on relations of mastering of the content of subjects of one educational sector or between sectors; for example, mastering of the program "Forming of pupils' general scholastic skills and abilities".

- metasubject - determine the level of mastering of the key competences as universal abilities of an individual (ability to learn, general cultural, civic, communicative, health-saving, informational, social, entrepreneurial) by pupils.

As we see, the resultative effect of the educational process in educational activity concerns personal, subject-related, intersubject and metasubject achievements of a pupil. The components of the educational result differ in the way of forming and the breadth of application, but they are closely related. Thus, the subject-related results are manifested in subject-related competences regarding which the program has clear guidelines as for the levels of their mastering; they can be tested and evaluated by the teacher under the evaluation criteria and standards. The quality of a pupil's subject-related competences depends on his value orientations (let us say, responsible attitude to learning, cognitive interests and so on), and his ability to learn.

At the same time, intersubject and metasubject kinds of educational results of the pupils are formed when they participate in subject-related activities at various lessons, taking into account the life experience and environment in which a child is developing. This relationship is organic for elementary school because it is an integrated systematic, multisubject element with a long-time and considerable influence of one teacher. In this process it is extremely important to achieve as high as possible efficiency of each lesson.

According to the conducted studies, interpretation of developments in the theory of contemporary lesson, we define a set of provisions that should be taken into consideration in its modeling on the basis of competence approach.

2. In modeling of a system of lessons and of a separate lesson it is necessary to reach a mutually agreed determination of the objectives and the expected result. For this it is necessary to analyze the hierarchy of objectives and results of the subject study in the following order: the state standard - curriculum - section system of lessons - a lesson. It reveals the viability and continuity in the formation of subject-related competencies and it will prevent the overloading of a separate lesson and will orient a teacher on a timely accompanying and thematic control. These steps will help to make a system of lessons, rather than a separate lesson, the object of a teacher`s attention. Under this condition it is more realistic to 
determine the objectives and expected results of learning both of a topic (section) in the whole, and of an individual lesson.

The teacher defines the objective of a lesson from two angles: for himself or herself and for pupils. For pupils it can be represented in the tasks of the lesson that can be conveyed through short utterances (1-3 words) or through conventional symbols (a road map of a lesson).

The observation of lessons, the study of published scenarios show that in the teachers' plans predominate voluminous, excessive objectives and tasks, while real capabilities of the lesson time and selected educational material are little taken into account. The specification of the lesson result takes place even in a more difficult way. Still, if the teacher first defines the objective and predictable results for the whole topic (section), then it is much easier and clearer to define them for an individual lesson. As for the expected results, it is necessary to take into account that at the lesson involved are both background, mediated knowledge, and the new one, that children are just beginning to master. And the abilities, skills and ways of working, as you know, are formed for a long time, not for 1 or 2 lessons. That is why it is necessary to take into account the didactic difference between the objectives to teach, develop, shape and form in the objective and tasks of the lesson. Only the last objective implies such state of the pupil's readiness which should be achieved and can be checked.

3. In the achievement of any competence the basis is active, purposeful and conscious activity of pupils. The means of such activities at the lessons are the operations, pupils' actions that are revealed in academic interaction. It presupposes subject-subjectivity of learning (teacher-pupil, pupil-pupil, group-group), which becomes polysubject if the boundaries of the activities at the lesson are expanded by means of the environment (through ICT), children's life experiences, attracting new educational resource.

Subjectivity of educational interaction appears multifaceted. It should be childcentered and focused, make a specific contribution to the pupils' achievement of educational results. For this it is necessary to take care, first of all, about motivational support of the process of learning during the system of lessons; provide a wide range of incentives to be able to support and strengthen the training motives of various groups of children and of an individual pupil, since motivation, the need for independent activity is a deeply individual sphere.

In the formation of subject-related competences especially necessary is the usage of individual tasks, taking into account the levels of pupils' readiness to master new material of the lesson and achieving of the planned results in accordance with their capabilities and fulfillment of tasks for choice which form the self-esteem and responsibility.

4. An important condition of organization of a fully-fledged subject-subject interaction is taking into consideration of the children's life experience and a psycho-didactic environment of the lesson which proves the teacher's real concern about emotional and mental well-being of children during learning, when they can choose a task and talk about themselves (express reflexive judgment). If the pupil is the subject of learning, it excludes teacher's manipulation by his consciousness, behavior of extrusion of expected results at any price, by reducing children's time for having rest, neglecting relaxing and game situations.

5. The technological approach as a tool for achievement of expected learning results by pupils. 
In didactics there exist different definitions and classifications of concepts related to the research and implementation of a technological approach into school practice. In our study, we use the term educational technology which is used in the following meanings: it is an ordered set of actions and operations, which content and sequence provides a gradual management of the learning process aimed at gaining the planned educational results by pupils. Respectively, the educational technology has the content, procedural, resultative and reflective parts.

Educational technologies belong to the humanities, which are non-linear, because each situation is influenced by a number of indeterminate factors - that is why they presuppose flexibility and interaction between teachers and pupils and can be presented in the form of both simultaneous and schematic description of the actions of teachers and students. The advantage of the technological approach is that it has activity-based foundation, foresees acquiring by pupils of their personal experience in mastering of certain ways of action, and therefore it is centered on their practical activity, without which it is impossible to form subject-related competence. Scientists define the basic qualities of educational technologies in the following way: a conceptual idea, consistency, handling of actions, efficiency, reproducibility. (G. Selevko, V. Monakhov, S. Sysoyeva, A. Khutorskyi, O. Pometun and others).

In terms of the levels of technologies application in the primary education we distinguish general pedagogical, methodical and local technologies.

In the development and application of educational technologies in the system of lessons the starting condition is the correct definition and clear wording of the objectives of learning by the teacher. General, vague objectives do not contribute to choosing of the methodological tools which direct pupils' actions in learning to the achievement of the result. So the very first step in the usage of any educational technology is correctness and specificity of the learning objective. Depending on the purpose of processing of the material the expected (forecasted) result is determined (Savchenko O. Ya., 2015: p. 5).

What exactly should the pupil master: learn the rule, remember a definition, apply the course of action on the model, apply it in new conditions, etc.). The requirements of the curriculum to the pupils' educational achievements are a reliable guide in specifying a learning result concerning subject-related competences. The structure of these requirements correspond to the structural elements of subject-related competences: knowledge, understanding and experience of application, revealing of value-related attitude to the process and result of the activity.

The way from the objective of the lesson to the expected results is the interaction between a teacher and pupils organized in a certain way (stepby-step). Under the technological approach all the teacher's actions should economically and purposefully lead pupils step by step, making closer the achievement of a determined objective. That is why, the educational technology, in addition to the objective and expected results of learning, includes a description of the procedures by which it is possible to achieve this very result.

Educational technology must have clear procedural characteristics: clearly and unambiguously describe what and in which sequence to do, make it possible for every teacher who uses it, to organize pupils' learning for achievement of the planned result. Here is the difference between a technological approach and methodical references, since the methods presuppose a variety of ways to reach the objectives which allow modification and do not guarantee the expected result. The educational technology also may change during the correction of the achieved result. For example, finding out the pupils' results at the intermediate stage of the 
educational process, the teacher introduces corrections and changes into the pupils' further actions. That is why, in the application of the educational technology mandatory is accompanying operational feedback between a teacher and pupils' achievements.

In the view of the aforesaid, there arises a question about the possibility of a teacher's creative work in the application of educational technologies. As far as they are focused on reproductive situations of learning, we believe that pedagogical creative work can find its place on the stages of correction of teachers' and students' actions on the way for achievement of the expected results.

Teachers often underestimate the importance of compliance with all the conditions of educational technology application, snatching out a few elements that seem most interesting to them.

For example, the teacher likes to use such playing methods as "Microphone", "Role Play" in the interactive technology, but for working out all the ways of action, which are also foreseen by this technology, there was not enough time. In this case, we cannot consider that an integral educational technology is applied, and therefore, there is no ground to hope for the completeness of achievement of the expected result.

The impact of the educational technology on the quality of the pupils' performance results depends on the manner in which they are achieved. In this regard, while using an educational technology it is extremely important to select the content of exercises, tasks and determine their volume and ways of a mutuallyreciprocal feedback.

As a result of a long study, conducted together with L. V. Koval, there was generalized a set of efficient educational technologies that are intersubject in nature. Their use in elementary school allows to organize the learning process as individually oriented one, adapt it to the conditions of learning (specificity of the content, the level of program requirements, readiness of children, etc.) in order to achieve the intended result (Koval L. V., 2009: p. 69-99).

- Technology of complete learning (J. Carroll, B. Bloom, M. Klarin). In this technology a constant parameter is the result of learning, and learning conditions are variables that are adapted to achieving the expected result by pupils. This technology realization requires a reorganization of the existing class-task system primarily towards combination of small organizational forms of learning: dyad triad - group of 4-5 pupils, one pupil and others.

Under this technology basic are the three notions: the purpose of learning (knowledge, comprehension, application, analysis, synthesis, self-esteem), pupils' actions, the result of action (Klarin M. V., 1998: p. 223).

The technology of learning interaction organization between a teacher and pupils through dialogue and polylogue where the teacher and pupils are the subjects of learning. This technology includes methods of pedagogical support of lagging pupils (Savchenko O. Ya., 2015: p. 5).

- Technology of forming of general educational skills in junior schoolchildren using the indirect influence and gradual management of the learning of the essence of a skill by pupils and the ways of its application. (P. Halperin, N. Talyzina V. Palamarchuk, O. Savchenko).

- Technology of differentiated learning in accordance with the levels of the pupils' readiness, which presupposes self-assessment of one's readiness and stepped learning of the material, with the choice of the extent of the teacher's help and others (Logachevska S. P., 1998: p. 5). 
- The technology of the educational project activity is oriented on independent research and creative work of pupils (individual, group, collective) for comprehensive learning of the object; research, informational, creative and role projects; monoproject and metasubject); mastering project and research skills; gaining the experience of cooperation and work with different sources of information. (U. Kh. Kilpatrick, I. G. Yermakov, O. V. Onopriyenko and others).

- The interactive learning technology is based on attracting younger pupils to interactions in solving learning situations and learning problems. Here the student becomes the subject of learning; he realizes his learning actions, expresses reflective judgment.

- The technology of advanced teaching, the essence of which is in a long-term preparation of children for mastering of complex methods of action (S. Lisenkova).

- Technology of combination of organizational forms of educational cooperation within the system of lessons and each lesson. (M. Cheredov, A. Yaroshenko and others).

In elementary school collective forms of work traditionally dominate at the lessons. As for the way of perception and activity they involve the usage of various methods and techniques of learning, putting activating questions, and they contribute to the forming of collective learning result. At the same time, under these forms of work, the level of development, cognitive interests and capabilities of individual pupils are usually not taken into account, here prevails a unilateral way of communication; the possibilities of organization of mutual aid among children and self-examination fulfillments are limited.

It is believed that individual work does not have these drawbacks, because it provides for a higher level of pupils' self-dependence, makes it possible to take into account their development more accurately, to set their natural pace in learning and that it actively shapes their cognitive needs. But individual work will give an appropriate return only if the teacher has diagnostic skills, uses individual tasks in a certain system, prevents the development of successful pupils' arrogance and timely stimulates "weak" children.

Under a group form of work the ability to cooperate is developed in elementary school children; the conditions for gaining experience of interpersonal communication, mutual learning, moral learning motives and the ability to spend time rationally are formed; opportunities for multivariate approaches to solving a problem are created. If group work is not organized appropriately, the rhythm of the lesson is violated, some children do not work in full force, waiting for ready results as observers, they are not able to comply with the general requirements. Collation of didactic opportunities of frontal, individual and group work shows that each of them has its "pros and cons", so choosing one or another kind of cooperation of pupils, a teacher must foresee its impact on the achievement of the expected results by most pupils.

For the purpose of selecting and evaluating the opportunities for application of didactic technologies on the methodological level we recommend the following algorithm of the teacher's actions:

- analysis of the objective of an individual lesson and determination of its place (functions) in the context of the objective of a system of lessons;

- clear determination of the content and structure of the expected result in the format of requirements for pupils' educational achievements; 
- contrastive analysis, forecasting of the operations of the known technologies in terms of abilities of the pupils of a certain class to achieve the expected results;

- $\quad$ filling of structural elements of the technology with substantive content;

- prediction of methods of reciprocal communication with pupils during the application of the technology and the ways of correction of educational achievements;

- involving of pupils into self-reflection and self-evaluation of educational achievements comparing them with expectations; the teacher.

- reflective analysis of the effectiveness of the selected technologies by

\section{CONCLUSIONS}

Thus, the technological approach involves projecting and implementation of a system of a teacher's and pupils' actions aimed at achievement of a clearly-defined goal and expected results through consistent management of pupils' learning activities in conditions of operational feedback. The criteria for the effectiveness of educational technology are their commitment, controllability of the pupils' actions, the ability to replicate and measure the results and evaluation. The perspective is the development of methodological aspects of the technological approach and criteria basis of their effectiveness determination as a tool of formation of subjectrelated and key competencies.

\section{REFERENCES}

1. Curricula for general educational institutions with teaching in Ukrainian 1-4 classes (2011). Kyiv: Publishing House "Osvita".

2. Savchenko, O. (2015). The objective and the result of a lesson in the context of the competence approach. Elementary school, 3, 6-9.

3. Koval, L. (2009). Professional preparation of future teachers of the elementary school: technological component. Donetsk: Yugo-Vostok.

4. Klarin, M. (1998). Innovations in teaching: methods and analysis of foreign experience. Riga: "Experiment".

5. Logachevska, S. (1998). Approaching every pupil. Differentiation in every class. 